\title{
História, Educação e Cultura Escolar
}

Vera Gaspar

Um generoso convite me veio através da colega Professora Giani Rabelo para fazer uma intervenção no momento de apresentação pública do livro História, Educação e Cultura Escolar. O primeiro tema que me ocorreu foi falar do próprio, da "estrela da festa" que, vestida em trajes de gala-de vermelho e dourado, com fino acabamento - entra glamorosa, seduzindo os leitores, despertando desejo de posse e, com maestria, envolve e protege um conjunto de artigos apresentados inicialmente no XII Encontro Estadual de História - História, Ensino e Pesquisa, promovido pela Associação Nacional de História (Anpuh) Seção Santa Catarina. O evento foi realizado na Universidade do Extremo Sul Catarinense (Unesc) de 21 a 25 de julho de 2008 no simpósio "A cultura escolar nas pesquisas em História da Educação", a mesma Unesc que serve de cenário para o "desfile" desta noite.

\section{Dos Organizadores:}

Elison Antonio Paim: É mestre em História, doutor em Educação pela Universidade Estadual de Campinas e atua como Professor titular na Universidade Comunitária da Região de Chapecó - Unochapecó.

Giani Rabelo: É mestre em Educação, doutora em Educação pela Universidade Federal do Rio Grande do Sul. Atualmente é professora no curso de Pedagogia e no Programa de Pós-Graduação em Educação no Mestrado em Educação da Universidade do Extremo Sul Catarinense - Unesc.

*Profa. do Programa de Pós-Graduação em Educação do centro de Ciências Humanas e da Educação da UDESC 
Marli de Oliveira Costa: É mestre em História e doutora em Educação pela Universidade Federal do Rio Grande do Sul. Atualmente é professora dos cursos de Pedagogia e História da Universidade do Extremo Sul Catarinense - Unesc.

\section{Da inscrição teórica:}

A reflexão construída pelos organizadores na apresentação do livro indica a cultura escolar como eixo organizador das análises, alinhando-se ao tema do simpósio que reuniu, pela primeira vez, a maior parte dos trabalhos agora impressos em formato de livro. A cultura escolar é por eles anunciada como uma cultura produzida na escola e que "alcança os sujeitos que constituem a comunidade escolar ao longo da história, qual seja: alunos, professores, funcionários e comunidade de pais no cotidiano" (p. 9). Além de apresentar o livro, os organizadores retomam a forma como alguns autores de referencia abordam a cultura escolar, ou, mais adequado dizer, as culturas escolares e a própria cultura. Assim, são evocados Dominique Juliá, Antonio Viñao Frago, Antonio Molero Pintado e Angel Pérez Gómez. Aliam-se, aqui, elementos teóricos trazidos de Raymond Willians e Edward Palmer Thompson a respeito do conceito de cultura, provocando o necessário diálogo entre a escola e as relações sociais, nas palavras de Edward Thompson: "a arena de elementos conflitivos" (p. 14). Enfim, as culturas escolares são aqui inscritas como uma "multiplicidade de experiências e significados, em oposição à unicidade e à homogeneidade. Embora existam elementos comuns nos ordenamentos oficiais para as escolas, cada uma cria ou recria sentidos próprios, para cada local específico" (p. 14). Aliás, o desejo de escrever uma história da educação que capture o cotidiano e que traga para a cena seus atores é um elemento forte desta coletânea.

A inscrição teórica serve de baliza para operar a geografia do livro, materializada na forma de organização escolhida: "quatro 
partes" que poderíamos entender como quatro regiões de um grande território.

A Primeira Parte: "Memórias e histórias de escolas religiosas" reúne quatro textos escritos pelas mãos de Giani Rabelo, Elison Antonio Paim, Nanci Laufer Krindges, Vanessa Picolli e Fabiana Nicolau.

São textos que revelam a força da igreja católica no desenho da educação catarinense, sua relação com o Estado e parte das estratégias acionadas para educar o escolar e suas famílias. Parte das atenções da pedagogia praticada pelas instituições religiosas esteve voltada a ação profilática como forma de prevenção de doenças e civilização dos corpos. Um trabalho de profilaxia onde as religiosas educavam não só para a limpeza e organização dos lares como também pra a higienização de costumes e hábitos "a fim de prevenir conflitos entre as famílias, entre os próprios trabalhadores e entre os trabalhadores e seus patrões" (Rabelo, 2012: p. 30). As pedagogias missionárias se ocupavam, também, em professar o anticomunismo católico seja no discurso, na pregação, seja nos conselhos e receitas de organização de um aconchegante lar pronto a espera do exaurido operário que deveria preferi-lo à rua ou aos sindicatos. Mas, como mostra Giani Rabelo, isto não se dá sem resistência e as mulheres dos mineiros são exemplares nisto.

De espaço geográfico oposto, no oeste catarinense, vem a experiência que inspira e sustenta análise sobre a atuação de religiosas católicas em São Lourenço do Oeste em meados do século XX. Do ponto de vista da produção historiográfica, Elison Paim e Nanci Krindges advertem que se trata de um ponto de vista, de um olhar, de uma forma de ver e analisar. Esta advertência é reveladora de opções teóricas e de uma postura acadêmica salutar, particularmente quando se trata da escrita da história ou, como gostariam os autores, de uma história. Neste olhar, colonizar, rezar e educar se conectam numa "teia de relações" permeada de disputas, tensões, conflitos e adesões, 
um emaranhado de difícil compreensão mas que não se pode desprezar quando se pretende mergulhar na compreensão da constituição do campo educacional catarinense (e brasileiro).

Outro grupo religioso serve de objeto para o trabalho de Vanessa Picolli, trata-se das Irmãs de São Jose de Chamberry vindas da França para o Brasil em meados do século XIX, mas instaladas no oeste catarinense apenas na década de 60 do século seguinte. Ocupadas especificamente do ensino voltado para meninas e moças e agregadas a outros grupos imbuídos de institucionalizar a educação, assumem uma prática que durante bom tempo se organizou de modo doméstico ou menos formal. Nas linhas traçadas por Vanessa Picolli, vemos, mais uma vez, o cuidado com escrita da história e ela traz a cena Albuquerque Júnior para reforçar sua posição

[...] damo-nos conta de que a história não está a serviço da memória, de sua salvação, mas está, sim, a serviço do esquecimento. Ela está sempre pronta a desmanchar uma imagem do passado que já tenha sido produzida, institucionalizada, cristalizada. Inventando a partir do presente, o passado só adquire sentido na relação com este presente que passa. (Albuquerque Júnior, 1995, p. 61).

Fechando a primeira parte do livro, temos uma reflexão de caráter metodológico, debruçada sobre a produção de fontes. Mas, que tem por base mais um grupo religioso responsável pelo Colégio Salesiano de Itajaí, ocupado da educação masculina. No texto, Fabiana Nicolau problematiza "a emergência e a utilização de documentos fabricados no interior da instituição escolar e a possibilidade de utilizá-los para análise e compreensão das culturas escolares e da consequente produção de sujeitos" (pg. 89) e nos brinda com uma excelente reflexão sobre a lida com as fontes ou, em suas próprias palavras, o trato com os documentos tratados como peças cheias de intencionalidade. Afinal, como 
nos ensina Jacques Le Goff:

"Nenhum documento é inocente. Deve ser ajuizado. Qualquer documento é um monumento que é preciso saber decompor, desmontar. O historiador não deve ser capaz de distinguir um documento de falso e avalizar a sua credibilidade; deve também saber desmitificá-lo. Os documentos só passam a ser fontes históricas depois de sofrerem um tratamento destinado a transformar a sua função de mentira em confissão de verdade. (2000, p. 104 Apud Nicolau, 2012, p. 99-100).

A Segunda Parte: "Memórias e Histórias: reminiscências escolares" é composta pelos trabalhos de Marli de Oliveira Costa, Cinara Lino Colonetti Bergmann, Paulo Sérgio Osório e Tatiane Virtuoso.

Esta parte do livro tem início com artigo de Marli Costa sobre os livros da Série Fontes, idealizada pelo inspetor da Instrução Pública de Santa Catarina Henrique Fontes e publicada nos anos 20 do século passado. De suas páginas, a autora desnuda a intencionalidade de um conteúdo dedicado a "construir um homem civilizado" e que, "junto com a ideia de civilizado, expressa as virtudes que deveriam ser inscritas nas crianças desde cedo" (p. 109). São textos que através de conteúdos de religião, ciências, história e civismo investem na formação de condutas, hábitos e identidades.

Cinara Bergmann trata de tema poucas vezes abordado na perspectiva histórica: a "educação especial" e toma por fonte memórias de jovens com necessidades especiais que frequentaram a instituição estudada, a Escola Municipal Professor Moacyr Jardim de Menezes. Nas marcas de uma escola regular na vida de alunos com necessidades especiais, o texto traz a tona uma problemática ainda muito cara às instituições e políticas educacionais e entrecruza olhares de mães, alunos e professores tecendo uma rede onde diferentes sensações - 
desconforto, frustração, otimismo, aposta dão o tom do desafio que é lidar com esta problemática. Ao mesmo tempo, a autora ressalta a importância do papel da instituição e de seu corpo docente na acolhida e suporte a alunos e familiares como armas na construção de um mundo mais justo e humanizado.

Pelas mãos de Paulo Osório, vemos surgir uma escola construída pela iniciativa de uma professora e dedicada ao atendimento de uma camada social, cultural e economicamente privilegiada, num processo que também revela tensões: uma professora oriunda das classes médias, que pela morte do pai se vê obrigada a trabalhar e encontra na educação e na aliança com as famílias mais abastadas um caminho para sua sobrevivência.

Tatiane Virtuoso trabalha com reminiscências da cultura escolar das primeiras décadas do século XX, construídas num dúbio contexto identitário, dividido entre símbolos nacionais italianos e brasileiros. A materialidade escolar construída com elementos que representam estas duas culturas e suas linguagens entram em disputa, alijam-se até que, oficialmente, os artefatos da cultura italiana são amordaçados por força de lei, mas como apresenta a autora, se mantém como suportes nas memórias; são elementos cujo escrutínio e compreensão se colocam como necessários para se entender o jogo de táticas e estratégias acionados pela população das área de "colonização".

A Terceira Parte: "Educação Indígena" traz três artigos de autoria de Helena Alpini Rosa, Ana Lúcia Vulfe Nötzold, Leonel Piovezana e Talita Daniel Salvaro

O primeiro, escrito por Helena Alpini Rosa e Ana Lúcia Vulfe Nötzold, trata de uma das expressões da cultura indígena ao abordar a educação Guarani e a presença da escola nas comunidades Guarani do Morro dos Cavalos e de Massiambu no município de Palhoça, sul de Santa Catarina. Assim como no texto que trata das tensões entre a cultura italiana e a "brasileira", vemos um "embate cultural" representado por diferentes formas de viver, diferentes valores, diferentes formas 
de expressão. A cultura indígena, já fortalecida por um estatuto social que a coloca como cultura, mantém-se num lugar de disputa com a cultura urbana, tida ainda muitas vezes como sinônimo de civilização. Mas, a escolarização é percebida pela comunidade indígena também como via de entrada de projetos políticos e sociais e via de acesso na construção de caminhos que estabeleçam conexões com outros segmentos sociais e que produzam conquistas políticas.

Seguindo essa temática, Leonel Piovezana aborda a luta de povos guaranis e kaingangs na defesa de um território "uma luta pela terra, não por documentos". A defesa de um território vem acompanhada da defesa de uma educação diferenciada, bilíngue e intercultural que coloca em pauta outro desafio, a formação de professores bilíngues e a capacitação de professores índios.

$\mathrm{Na}$ esteira desta discussão, vem o texto de Talita Daniel Salvaro e Ana Lúcia Vulfe Nötzold, que se debruçam na reflexão da complexidade que envolve a construção das escolas indígenas brasileiras que não podem ter todas o mesmo desenho. Sem respeitar as diferentes etnias, o estabelecimento de uma escola indígena única redundaria num mecanismo tão opressor como a aquela levada a efeito por missionários e diretores de aldeamento.

Enfim, o conjunto de textos aglutinados na temática da Educação Indígena que compõem a Terceira Parte, dizem muito dos desafios de nossa época.

A Quarta e última Parte "Formação de professores" reúne artigos escritos por Maria de Fátima Rodrigues Pereira, Elza Margarida de Mendonça Peixoto, Elison Antonio Paim e André Luiz Onghero.

O texto de Maria de Fátima Rodrigues Pereira e Elza Margarida de Mendonça Peixoto traz um importante contributo ao apresentar um mapeamento das pesquisas e dos debates sobre formação de professores, contemplando referências internacionais, nacionais e locais. Do cenário brasileiro, as 
autoras destacam entidades que se ocupam ou tem participado das principais discussões, periódicos que tratam ou trataram o tema, dados sobre a produção ancorada em programas de pósgraduação, eventos nacionais e internacionais dedicados a este debate. Ao concluir, reafirmam que "a formação de professores é uma questão em conflito que exige dos educadores tomada de posição a favor dos interesses da classe trabalhadora" (p. 250).

O segundo texto desta parte do livro tem como autor Elison Paim que coloca em pauta um tema de grande relevância tanto para a história da educação brasileira quanto para a discussão de nossa escolarização: as práticas desenvolvidas em escolas multisseriadas. "Afinal, quem eram esses homens e mulheres que assumiam a tarefa de escolarizar crianças?” (p. 254). Dando voz aos professores e professoras, o autor vai remontando e dando visibilidade a um cotidiano na maior parte das vezes excluído de nossas narrativas históricas, mas que no caso brasileiro foi, durante muitos anos, o responsável por assegurar o pouco de escolarização que nossa população teve acesso.

O livro termina com trabalho de André Onghero dedicado à formação de professores de Educação Moral e Cívica. $\mathrm{Na}$ contramão de um discurso bastante comum e que coloca esta disciplina como forte componente ideológico e bastante monitorada, o autor traz elementos que indicam que os professores dispunham de certa autonomia, que esta foi muitas vezes uma disciplina de menor importância e que cumpria um papel suplementar na composição da carga horária de professores de outras matérias ou áreas.

\section{Recorte Temporal}

Do ponto de vista temporal, a maior parte dos artigos se dedica a investigação e reflexão de aspectos da cultura escolar da escola catarinense da última metade do século XX. 


\section{Fontes:}

Quanto às fontes, todos os textos passam, de alguma forma, pela história oral lançando mão de entrevistas disponíveis em acervos ou de "entrevistas provocadas"; as vozes de alunos, professores, familiares são consideradas como elementos balizadores.

Alia-se, aqui, uma variedade de "outras fontes", são relatórios produzidos pelas instituições analisadas, acervo documental produzido e/ou guardado pelas instituições, livros de memórias, acervos particulares como o da professora Zulcema Póvoas Carneiro, legislação do ensino e documentos internacionais. Esta variedade de fontes permite o levantamento ampliado de informações:

"O cotejamento de fontes insere o pesquisador num mundo de atritos, lacunas e insubordinações. Nesse sentido, as fontes confrontam o historiador, colocando-o mediante um mosaico de dados conflitantes que se tornam inteligíveis por meio do trabalho da escrita da história. A construção de uma inteligibilidade pretende alcançar representações e construir uma história possível, a partir das fontes de que se dispõe." (Virtuoso, 2012, pg. 163)

\section{Referencias Teóricos:}

Alguns autores aparecem nos textos de forma recorrente com destaque para Déa Ribeiro Fenelon com as obras "A formação do profissional de História e a realidade do ensino", "A Questão de Estudos Sociais", "O historiador e a cultura popular", "Cultura e história social: historiografia e pesquisa", "Pesquisa em História: perspectivas e abordagens" e o trabalho organizado em parceria com Laura Maciel Antunes, Paulo Roberto Almeida e Yara Khoury "Muitas memórias, outras histórias".

O segundo autor mais recorrente é Edward Palmer 
Thompson com os trabalhos "A formação da classe operaria inglesa", "A miséria da teoria: ou um planetário de erros" e "Costumes em comum: estudos sobre a cultura popular tradicional".

Em destaque também se encontra Michel Foucault com as obras "Eu, Pierre Riviere, que degolei minha mãe, minha Irmã e meu irmão" na qual integra a equipe de organização, "A microfísica do poder", "A ordem do discurso" e "Vigiar e punir".

A seguir, temos Roger Chartier com as obras "A beira da falésia: a história entre incertezas e inquietude", "Textos, impressões, leituras", Alessandro Portelli com "Forma e significado na História Oral: a pesquisa como um expediente em igualdade", "O que faz a história oral diferente" e "Tentando aprender um pouquinho: algumas reflexões sobre ética na História Oral", Elison Antonio Paim com os trabalhos "Fala professor(a): o ensino de História em Chapecó (1970-1990)", "Industrialização e Educação", "Memórias e experiências do fazer-se professor(a) de História" e, Sílvio Coelho dos Santos com "A integração do índio na sociedade regional: a função dos postos indígenas em Santa Catarina", "Educação e sociedade tribais", "Povos indígenas de Santa Catarina" e "Povos indígenas do Brasil: direitos constitucionais, terras e lutas presentes".

Há um conjunto de outros autores e obras que influenciam a feitura dos textos, mesmo que nem sempre sejam diretamente citados, entre eles Michel de Certeau, Philippe Ariès, Walter Benjamin, Norbert Elias e Pierre Bourdieu.

O conceito de cultura escolar é tratado com base em dois teóricos cuja presença nas discussões e produções de História da Educação brasileira tem sido marcante, trata-se de Antonio Viñao Frago e Dominique Julia.

As indicações acima não têm por fim organizar um ranking 
“dos mais lidos ou mais importantes".Mas, sim, tentar identificar a força e circulação de determinados autores e obras em nosso meio. Chama a atenção, no conjunto do livro, a tímida presença de autores consagrados na história da educação brasileira e a quase ausência da produção catarinense, dados que reforçam o argumento acerca da necessidade premente de eventos que agreguem a produção estadual e a façam circular entre os pares, afinal, precisamos nos conhecer.

Por fim, trata-se da reunião de um conjunto de artigos com origem em trabalhos em diferentes estágios de amadurecimento: de pesquisas em andamento a teses de doutorado, escritos por bolsistas de iniciação científica, alunos de pós-graduação ou pesquisadores já consolidados (para utilizar uma expressão do jargão acadêmico). Se, por um lado, esta composição traz as fragilidades de trabalhos mais incipientes; por outro, ela tece uma rede colaborativa entre sujeitos que se debruçam sobre a HE e agrega elementos que favorecem a compreensão de um intricado jogo que vai desenhando as culturas escolares. 